\title{
Analysis of correlation of CYR61 and MTHFR Gene Polymorphism in Legg-Calve-Perthes disease
}

\author{
Article by Ajai Singh ${ }^{1}$, Sabir Ali ${ }^{2}$, Syed Rizwan Hussain ${ }^{3}$, Vineet Kumar ${ }^{1}$, Abbas Ali Mahdi ${ }^{4}$, \\ Rajeshwar Nath Srivastava ${ }^{1}$ \\ ${ }^{1}$ MS, Department of Orthopaedic Surgery, King George's Medical University \\ ${ }^{2}$ MSc, Department of Orthopaedic Surgery, King George's Medical University \\ ${ }^{3} \mathrm{PhD}$, Department of Orthopaedic Surgery, King George's Medical University \\ ${ }^{4} \mathrm{PhD}$, Department of Biochemistry, King George's Medical University \\ Email: as29762@gmail.com
}

\begin{abstract}
Background: Legg-Calve-Perthes disease (LCPD) is one of the most common causes of paediatric femoral head osteonecrosis. Besides the other known etiological aspects, till now genetic aspect has not been studied extensively. The present study was aimed to find the association of genetic polymorphism of CYR61 and MTHFR gene with the LCPD.

Materials and Methods: Single Nucleotide Polymorphisms (SNPs) analysis of the CYR61 and MTHFR genes in 41LCPDpatients and 110 healthy controls were genotyped in this hospital-based study by polymerase chain reaction and restriction fragment length polymorphism (PCR-RFLP).

Results: The frequency of CYR61gene homozygous mutant GG polymorphism was not significant in LCPD patients when compared with controls.MTHFRC677T homozygous mutant TT polymorphism was significant in LCPD patients as compared to controls.

Conclusions: The present study showed a significant association of T allele of MTHFR C677T polymorphism with LCPD and may be regarded as a risk factor to develop the LCPD in North Indian patients.
\end{abstract}

Keywords: Perthes disease, CYR61, MTHFR, Etiology of Perthes disease, Risk factors of Perthes disease

\section{Introduction}

Legg-Calve-Perthes disease (LCPD) is the clinical manifestation of vascular compromise of femoral capital epiphysis having unknown etiology, primarily affecting children between 4-12 years of age. This most often happens when the lateral epiphyseal vessels the primary source vascular supply of the femoral capital epiphyseal region are involved[1]. The annual incidence of LCPD in children below 15 yrs of age ranges from 0.2 to 19.1 per $100 \quad 000$ [2]. LCPD has usually an asymmetric presentation with only $15 \%$ of cases having bilateral involvement. Incidence of LCPD is 3-4 times more in boys than girls and is mainly occurs in children exposed to maternal smoking during pregnancy, low birth weight neonates, low socioeconomic groups, and children of white ethnicity [2-5].The affected children are relatively short stature and have delayed osseous growth [6]. Exact pathogenetic mechanism of LCPD is still unknown and it may probably cause a multifactorial etiology which still remains a question [7].

Most of the cases of LCPD not require any specific treatment as most of them are selflimiting and resolving in nature [8]. Moreover, among many children primary complaint is a painless limp \{but all cases with limp (painful/painless) in children of this age group are not LCPD [9]. Further, according to literature, only half of the cases of LCPD are diagnosed in their advanced stages, despite having complained of pain or a limping gait. Thus it is not surprise that a huge number of LCPD patients in their initial stages are missed due to which the actual incidence revealed in literature is probably just a tip of an iceberg.

The cysteine-rich protein 61 (CYR61) regulated by 1 alpha, 25-dihydroxyvitamin $\mathrm{D}(3)$ $(1,25-(\mathrm{OH})(2) \mathrm{D}(3))$, belongs to the growing CCN (CYR61/CTGF/NOV) family of immediate 
South American Journal of Clinical Research

Special Edition 2016

early genes, which modulate angiogenesis process, cell growth as well as cell proliferation and differentiation. The CYR61 gene acts as a growth factor in fetal human osteoblasts, identified as an extracellular matrix-associated protein that modulates basic fibroblast growth factor signalling, angiogenesis, and binds to integrin alpha(v)beta(3). CYR61 is secreted in primary osteoblasts and suggests that CYR61 gene might function as an extracellular signalling molecule in human bone [10].

Folate is a methyl donor during DNA methylation, as it provides substrate for MTHFR to convert 5, 10 MTHF to 5-MTHF and subsequently metabolise it to methionine [11]. MTHFR is involved in DNA methylation and the availability of uridylates and thymidylates for DNA synthesis and repair [12].In humans, under such circumstances, allele $\mathrm{T}$ of C677T associated with greater enzyme sensitivity to reduce availability of 5-MTHF, would maintain the required supply of 5, 10-MTHFR for nucleotide synthesis. Previously, it has been reported that MTHFR gene polymorphism genotype was involved in LCPD[13].

Till date despite having detailed characterization of clinical and radiological features of LCPD, its etiology still remains essentially unknown [14,15].Although, it may be thought that both environmental and genetic factors have a role to play in development as well as its progression of LCPD [16]. It has been also been shown in experimental models that disrupted blood supply and infarction of the femoral head cause changes similar is seen in MRI/HPE of head femur of LCPD patients [17].

Previous studies have reported that apoptosis of osteoblasts and osteoclasts is a strictly regulated process and plays vital role in physiological bone turnover and in the development of pathological conditions in skeleton [18], but none of the studies have questioned this mechanism as an etiopathogenesis in LCPD patients so far. Alter inosteogenesis/bone remodelling is the one of the most important factor in the pathophysiology of LCPD, which leads to development of severe deformity in the affected hip[19].

CYR61 gene has a major contribution role in the process of osteogenesis as well as angiogenesis, which are the major factors that involved in the pathogenesis of LCPD. As it is well known that MTHFR polymorphism genotype associated with LCPD [13].So we planned this study to find the association if any, of genetic polymorphism of CYR61 and MTHFR gene with the LCPD.

The role of this single nucleotide polymorphism (SNP) involving CYR61 gene in LCPD, if proved, may open new horizons for innovations in this field with an addition to our armamentarium to deal with complications associated with LCPD, and to diagnose LCPD in initial stage which might reveal exact burden of this disease and standardize and improved treatment protocols.

\section{Materials and methods}

In this case-control study, we enrolled 41 cases of LCPD and 110 healthy controls. The study was carried out in the Department of Orthopaedic Surgery and Department of Biochemistry, King George's Medical University, Lucknow. The Institutional Review Board and Ethics Committee approved this study and it was carried out during January 2012 to July2015. Before enrolment, each parent/guardian's written informed consent was obtained in response to a fully written and verbal explanation of the nature of study.

All the patients with age between 4- 14 years with clinic-radiologically proven LCPD of either sex reporting within first year of onset of symptoms were enrolled as cases. However, patient with age less than 4 or more than 14 years, having known or symptomatic cardiovascular disease, active or chronic infection or malignancy, history of drug consumption e.g: anticancer, steroid, cases of known congenital dysplasias or sickle cell anaemia, history of direct injury of the hip, immune-compromised patients as well as known case of chronic disease like kidney malfunction, liver disorders, hypothyroidism etc. were excluded from case enrolment.

The diagnosis of LCPD in cases was established according to standard clinical criteria: onset of groin pain, disturbed stance on the affected leg and waddling gait, limitation of hip 
joint movements, especially abduction and internal rotation and absence of clinical signs suggesting trauma or infection. The radiographic signs considered for establishing diagnosis of LCPD include condensation or fragmentation of the epiphyseal ossification center with or without loss of femoral head sphericity.

\section{Isolation of genomic DNA}

Whole venous blood $(2 \mathrm{ml})$ was collected in $0.5 \mathrm{M}$ EDTA vial and stored $-80^{\circ} \mathrm{C}$ from all cases. Genomic DNA extraction for molecular genetic studies was performed using the commercially available extraction kit (Bangalore Genei, India) and was stored at $-80^{\circ} \mathrm{C}$. The DNA concentration was measured with a Nanodrop ND-100 Spectrophotometer (Thermo Fisher Scientific Inc., Wilmington, DE).

\section{Analysis of the CYR61and MTHFR gene polymorphism}

The CYR61 and MTHFR gene polymorphism was analysed by the polymerase chain reaction (PCR) followed by restriction fragment length polymorphism (RFLP). Genomic DNA was amplified by (PCR Thermocycler (Applied Biosystems, Germany) using following PCR conditions: $95^{\circ} \mathrm{C}$ for 5 minutes, 39 cycles at $95^{\circ} \mathrm{C}$ for 40 seconds, $50^{\circ} \mathrm{C}$ (CYR61 gene) for 50 seconds and (MTHFR gene) $56^{\circ} \mathrm{C}$ for 40 seconds, $72^{\circ} \mathrm{C}$ for 50 seconds, and finally $72^{\circ} \mathrm{C}$ for 10 minutes. The primers used for amplification of the CYR61gene polymorphisms were as follows: forward primer 5' $^{\prime}$-CTTGCCTCTCACCTTCGCTGTTAA- $3^{\prime}$ and reverse primer 5' -GTCGTTTTGTTTGGTGATGCGA- 3' [20] and MTHFR gene polymorphism are as follows: forward primer 5'-TGA AGG AGA AGG TGT CTG CGG GA-3' and reverse primer 5'-AGG ACGGTGCGGTGAGAGTG- 3' [21]. Amplification was performed with $25 \mu \mathrm{l}$ PCR reaction mixture containing $100 \mathrm{ng}$ template DNA, $10 \mathrm{pmol}$ of each primer and 2X PCR master mixes (Fermentas, Germany). Amplification success of samples was monitored by $2 \%$ agarose gel electrophoresis. Thereafter the PCR products were subjected to digestion by KspAI enzyme (Fermentas, Germany) for CYR61 gene polymorphism and Hinf1 enzyme (NEB, UK)) for MTHGR gene polymorphism. The enzymatic mixture contained $0.8 \mu \mathrm{L}$ restriction enzyme $2 \mu \mathrm{L} 10 \mathrm{X}$ buffer, $10 \mu \mathrm{L}$ PCR products and $7 \mu \mathrm{L}$ distilled water and incubated overnight at $37^{\circ} \mathrm{C}$ for digestion. The digested product was run on 3\% agarose gel, electrophoresis at 70 volts for 1 hour. In cases with CYR61 gene polymorphism, an undigested $104 \mathrm{bp}$ band showed wild-type TT genotype, while two bands of 80 and 24 bp confirmed mutant GG genotype and three bands of 104, 80 and $24 \mathrm{bp}$ were detected in the heterozygous TG genotype [20] (Figure 1). Whereas in MTHFR gene polymorphism, an undigested 198bp band showed wild type CC genotype, while two bands of 175 and $23 \mathrm{bp}$ confirmed mutant TT genotype and three bands of 198, 175 and 23bp were detected in a heterozygous CT genotype [21] (Figure 2).

\section{Statistical analysis}

The significance of this study was evaluated by Chi-square test. Odds ratio (OR) was calculated as an estimate of relative risk of having disease according to the relative frequency of different genotypes among the cases as well as the controls. The association between the polymorphisms and fracture non-union was estimated by odds ratios (ORs) and their 95\% confidence intervals (CIs), which were calculated by unconditional logistic regression. Pvalue was considered significant at $<0.05$. The value was expressed in mean $\pm \mathrm{SD}$ (Standard Deviation).

\section{Results}

In our study we included 41 cases with LCPD out of which 29 were males and 12 were females. The calculated mean age of cases was $10.5 \pm 4.94$ years and that of 110 controls was $11.5 \pm 4.21$ years. All demographic characteristics of cases and controls were summarized in Table 1.All the cases and controls were successfully genotyped by PCR- RFLP. The results of the molecular analysis are showed in Table 2. The average CYR61 gene genotype 
South American Journal of Clinical Research

Special Edition 2016

frequencies of TT, TG and GG were calculated to be $36.6 \%, 51.2 \%, 12.2 \%$ in cases and $32.7 \%, 55.5 \%, 11.8 \%$ in controls respectively. The MTHFR gene genotype frequencies of $\mathrm{CC}, \mathrm{CT}$ and TT were calculated to be $58.5 \%, 34.2 \%, 7.3 \%$ in cases and $30.0 \%, 51.0 \%, 19.0 \%$ in controls respectively. In comparisons to controls, the CYR61 gene polymorphisms of genotype homozygous GG, heterozygous TG and TG+GG were not significant in cases. We also observed that the frequency of CYR61 gene polymorphism of mutant allele $\mathrm{G}$ in cases was not significant in comparison to controls (Table 2). Similarly in MTHFR gene polymorphism, $\mathrm{T}$ allele frequency in cases was significant in comparison to controls $(p=$ $0.0022)$. We examined, significant TT homozygous $(p=0.0202)$, heterozygous genotype ( $p$ $=0.0120)$ and a slight rise of CT $+\mathrm{TT}$ genotypes $(p=0.0025)$ in cases as compared to the controls.

\section{Discussion}

Legg-Calve-Perthes disease (LCPD) is a self-limiting disease of children mainly characterized by interrupted blood supply to the capital femoral epiphysis that may further leads to necrosis of the epiphysis [22].LCPD is the juvenile form of ischemic osteonecrosis of the femoral head that mainly affects the children between $2-12$, causing the femoral head deformity and premature osteoarthritis [23].The study was done by comparing the genotypes of cases with healthy controls of matched age, gender, haemoglobin and other characteristic risk. The present observational study was designed to examine the impact of CYR61 and MTHFR genes polymorphisms on LCPD.

The analysis of data obtained revealed that MTHFR gene $\mathrm{T}$ allele is significantly associated with the development of LCPD (OR $=2.49,95 \% \mathrm{CI}=1.40-4.40, p=0.0022)$. However, the CYR61 gene polymorphism of genotype is not associated with cases as compared to controls. Similar observation has been reported in study by Sanja et al., (2015), who concluded that MTHFR gene polymorphism of genotype is associated with LCPD [13].

In our study, C677Tvariant in the MTHFR gene polymorphism was associated with LCPD. It is interesting to note that the frequency of T allele of the MTHFR gene was rather high in our patient than the controls, pointing to the population specificity of frequency of this allele. Thisallele frequency in our population was similar with other Caucasian subjects [24], while the studies from Asia reported much lower frequency of these allele in their populations [2527].

In conclusion, we provide the first evidence supporting the genetic effect of a MTHFR gene polymorphism as a potential risk factor in cases with LCPD in north Indian population. The involvement of a high MTHFR T allele frequency observed in cases with LCPD in our subset of population (North Indian), it opens new horizons for further workup in this direction for prospective investigators, as the genetic pattern may affect the bone physiology and consequently lead to LCPD. The exact etiology for LCPD still remains a mystery, and so as a result we are still unable to determine the specific risk factors which are responsible for its occurrence and therefore we lack proper screening test at genetic level to predict the same. In our study we have found genetic association of a particular gene and identified allele with LCPD. As the sample size in our study is not large enough, so we insist further studies with large sample size to establish the statistical significance of this association which will further validate our conclusion. This can help in opening new horizons in the diagnosis as well as management of LCPD and will definitely help us to know the exact burden of this disease.

\section{Conflict of interest}

The authors have no conflict of interests in this article.

\section{Acknowledgements}

This study was supported by Department of Orthopedics Surgery with collaboration with Department of Biochemistry, King George's Medical University, Lucknow, Uttar Pradesh, India. 


\section{South American Journal of Clinical Research \\ Special Edition 2016}

\section{References}

[1] Bahmanyar S, Montgomery SM, Weiss RJ, Ekbom A. Maternal smoking during pregnancy, other prenatal and perinatal factors, and the risk of Legg-Calve-Perthes disease. Pediatrics.2008;122:e459- 464.

[2] Boccia S, Hung R, Ricciardi G, Gianfagna F, Ebert MP, Fang JY, Gao CM, Gotze T, Graziano F, Lacasaña-Navarro M, Lin D, Lopez-Carrillo L, Qiao YL, Shen H, Stolzenberg-Solomon R, Takezaki T, Weng YR, Zhang FF, van Duijn CM, Boffetta P, Taioli E. Meta- and pooled analyses of the methylenetetrahydrofolate reductase C677T and A1298C polymorphisms and gastric cancer risk: a huge-GSEC review. Am J Epidemiol.2008; 167: 505- 516.

[3] Catterall A. Legg-calve Perthes syndrome. ClinorthopRelat Res 1981, 158:41-52

[4] Campbell I G. Methylenetetrahydrofolate reductase polymorphism and susceptibility to breast cancer. Breast Cancer Res. 2002; 14: 1-4.

[5] Chung SM. The arterial supply of the developing proximal end of the human femur. J Bone Joint Surg Am.1976;58:961970.

[6] Chu X, Dong C, Lei R, Sun L, Wang Z, Dong Y, Shen M, Wang Y, Wang B, Zhang K, Yang L, Li Y, Yuan W, Wang Y, Song H, Jin L, Xiong M, Huang W. Polymorphisms in the interleukin 3 gene show strong association with susceptibility to Graves' disease in Chinese population. Genes Immun.2009; 10: 260- 266.

[7] De Inocencio J. Epidemiology of musculoskeletal pain in primary care. Arch Dis Child.2004;89:431- 434.

[8] Hall AJ, Barker DJ, Dangerfield PH, Taylor JF. Perthes' disease of the hip in Liverpool. Br Med J (Clin Res Ed). 1983;287:1757- 1759 .

[9] Kim HK. Legg-Calve-Perthes disease: etiology, pathogenesis, and biology. J PediatrOrthop.2011;31(2 suppl):S141- 146.

[10] Jandial S, Myers A, Wise E, Foster HE. Doctors likely to encounter children with musculoskeletal complaints have low confidence in their clinical skills. J Pediatr.2009;154:267-71.

[11] Jeong MC, Navani A, Oksenberg JR. Limited allelic polymorphismin the human interleukin-3 gene. Mol Cell Probes. 1998; 12: 49- 53.

[12] Joseph B, Varghese G, Mulpuri K, NarasimhaRao K, Nair NS. Natural evolution of Perthes disease: a study of 610 children under 12 years of age at disease onset. J PediatrOrthop.2003;23:590-600.

[13] Joseph B, Willoughby R. Perthes' disease: a review of contributions from the Asia-pacific region. Malays Orthop J. 2010;4: $1-8$.

[14] Kim HK. Legg-Calve-Perthes disease. J Am AcadOrthopSurg.2010;18: 676- 686.

[15] Kim HK, Morgan-Bagley S, Kostenuik P. RANKL inhibition: a novel strategy to decrease femoral head deformity after ischemicosteonecrosis. J Bone Miner Res.2006;21: 1946- 1954.

[16] Kim HK. Pathophysiology and new strategies for the treatment of Legg-Calve-Perthes disease. J Bone Joint Surg Am.2012;94: 659- 669.

[17] Lee ST, Vaidya SV, Song HR, Lee SH, Suh SW, Telang SS. Bone age delay patterns in Legg-Calve-Perthes disease: an analysis using the Tanner and Whitehouse 3 method. J PediatrOrthop.2007;27:198-203.

[18] Lechner A, Schutze N, Siggelkow H, Seufert J, Jakob F. The immediate early gene product hCYR61 localizes to the secretory pathway in human osteoblasts. Bone. $2000 \mathrm{Jul} ; 27(1): 53-60$.

[19] Molloy MK, MacMahon B. Incidence of Legg-Perthes disease (osteochondritisde formans). N Engl J Med 1966;275:988-90.

[20] Nagase Y, Iwasawa M, Akiyama T, Kadono Y, Nakamura M, Oshima Y, Yasui T, Matsumoto T, Hirose J, Nakamura H, Miyamoto T, Bouillet P, Nakamura K, Tanaka S. Anti-apoptotic moleculeBcl-2 regulates the differentiation, activation, and survival of bothosteoblasts and osteoclasts. J Biol Chem.2009;284: 36659- 36669.

[21] Nelitz M, Lippacher S, Krauspe R, Reichel H.Perthes disease: current principles of diagnosis and treatment. Dtsch Arztebl Int.2009;106:517- 523.

[22] Park BL, Kim LH, Choi YH, Lee JH, Rhim T, Lee YM, Uh ST, Park HS, Choi BW, Hong SJ, Park CS, Shin HD. Interleukin 3 (IL3)polymorphisms associated with decreased risk of asthma and atopy. J Hum Genet. 2004; 49: $517-527$.

[23] Perry DC, Machin DM, Pope D, Bruce CE, Dangerfield P, Platt MJ, et al. Racial and geographic factors in the incidence of Legg-Calve-Perthes' disease: a systematic review. Am J Epidemiol.2012;175:159-66.

[24] Sanja Srzentic, Gordana Nikcevic, Dusko Spasovski, Zoran Bascarevic, Zorica Zivkovic, Zorica Terzic-Supic, Dragana Matanovic, Valentina Djordjevic, Sonja Pavlovic, Vesna Spasovski. Predictive genetic markers of coagulation, inflammation and apoptosis in Perthes disease-Serbian experience. Eur J Pediatr.2015; 174: 1085-1092.

[25] Syed Rizwan Hussain ,Hena Naqvi , Syed Tasleem Raza, Faisal Ahmed, Sunil G. Babu, Ashutosh Kumar, Zeashan Haider Zaidi, Farzana Mahdi. Methylenetetrahydrofolate reductase C677T genetic polymorphisms and risk of leukaemia among the North Indian population. Cancer Epidemiology.2012; 36: 227-231. 
South American Journal of Clinical Research

Special Edition 2016

[26] Tao L, Chen J, Zhou H, Qin C, Li P, Cao Q, Li J, Ju X, Zhu C, Wang M, Zhang Z, Shao P, Yin C. A functional polymorphism in the CYR61 (IGFBP10) gene is associated with prostate cancer risk. Prostate Cancer Prostatic Dis. 2013; 16: 95- 100.

[27] Yamada R, Tanaka T, Unoki M, Nagai T, Sawada T, Ohnishi Y, Tsunoda T, Yukioka M, Maeda A, Suzuki K, Tateishi H, Ochi T, Nakamura Y, Yamamoto K. Association between a singlenucleotidepolymorphism in the promoter of the human interleukin-3 gene and rheumatoid arthritis in Japanese patients, and maximumlikelihoodestimation of combinatorial effect that two genetic locihave on susceptibility to the disease. Am J Hum Genet.2001;68: 674- 685.

Table 1. Demographic details of cases and controls.

\begin{tabular}{|c|c|c|c|}
\hline \multirow{2}{*}{ Characteristics } & Cases $(\mathbf{n}=\mathbf{4 1})$ & Controls $(\mathbf{n = 1 1 0})$ & p-value \\
\hline Age & $10.5 \pm 4.94$ & $11.5 \pm 4.21$ & 0.2254 \\
\hline Male & $70.7 \%(\mathrm{n}=29)$ & $55.5 \%(\mathrm{n}=61)$ & 0.0820 \\
\hline Female & $29.3 \%(\mathrm{n}=12)$ & $44.5 \%(\mathrm{n}=49)$ & 0.0931 \\
\hline Haemoglobin (Hb) & $12.25 \pm 3.25$ & $13.15 \pm 3.10$ & 0.0616 \\
\hline Lower limb (Right) & $23(56.1 \%)$ & - & - \\
\hline Lower limb (Left) & $13(31.7 \%)$ & - & - \\
\hline Bilateral lower limbs & $05(12.2 \%)$ & - & - \\
\hline
\end{tabular}

Table 2: Frequencies of alleles and genotypes of CYR61 and MTHFR genes polymorphism in cases and

\begin{tabular}{|c|c|c|c|c|c|c|c|}
\hline \multirow[t]{2}{*}{ Polymorphism } & \multicolumn{3}{|c|}{$\begin{array}{l}\text { CYR61 } \\
(T \rightarrow G)\end{array}$} & \multirow[t]{2}{*}{$\begin{array}{l}\text { Polymorp } \\
\text { hism }\end{array}$} & \multicolumn{3}{|c|}{$\begin{array}{c}\text { MTHFR } \\
(\mathbf{C} \rightarrow \mathrm{T})\end{array}$} \\
\hline & $\begin{array}{c}\text { Cases } \\
(n=41)\end{array}$ & $\begin{array}{c}\text { Controls } \\
(n=110)\end{array}$ & P-value & & $\begin{array}{c}\text { Cases } \\
(n=41)\end{array}$ & $\begin{array}{c}\text { Controls } \\
(n=110)\end{array}$ & P-value \\
\hline TT & $\begin{array}{c}15 \\
(36.6 \%)\end{array}$ & $\begin{array}{c}36 \\
(32.7 \%)\end{array}$ & - & $\mathrm{CC}$ & $\begin{array}{c}24 \\
(58.5 \%)\end{array}$ & $\begin{array}{c}33 \\
(30.0 \%)\end{array}$ & - \\
\hline TG & $\begin{array}{c}21 \\
(51.2 \%)\end{array}$ & $\begin{array}{c}61 \\
(55.5 \%)\end{array}$ & 0.0780 & CT & $\begin{array}{c}14 \\
(34.2 \%)\end{array}$ & $\begin{array}{c}56 \\
(51.0 \%)\end{array}$ & $0.0120^{*}$ \\
\hline GG & $\begin{array}{c}05 \\
(12.2 \%)\end{array}$ & $\begin{array}{c}13 \\
(11.8 \%)\end{array}$ & 0.0895 & TT & $\begin{array}{c}03 \\
(7.3 \%)\end{array}$ & $\begin{array}{c}21 \\
(19.0 \%)\end{array}$ & $0.0202^{*}$ \\
\hline $\mathbf{T G}+\mathbf{G G}$ & $\begin{array}{c}26 \\
(63.4 \%)\end{array}$ & $\begin{array}{c}74 \\
(11.8 \%)\end{array}$ & 0.0800 & $\mathrm{CT}+\mathrm{TT}$ & $\begin{array}{c}17 \\
(41.5 \%)\end{array}$ & $\begin{array}{c}77 \\
(70.0 \%)\end{array}$ & $0.0025^{*}$ \\
\hline T allele & $\begin{array}{c}51 \\
(62.2 \%)\end{array}$ & $\begin{array}{c}133 \\
(60.5 \%)\end{array}$ & - & C allele & $\begin{array}{c}62 \\
(75.6 \%)\end{array}$ & $\begin{array}{c}122 \\
(55.5 \%)\end{array}$ & - \\
\hline G allele & $\begin{array}{c}31 \\
(37.8 \%)\end{array}$ & $\begin{array}{c}87 \\
(39.5 \%)\end{array}$ & 0.0886 & T allele & $\begin{array}{c}20 \\
(24.4 \%)\end{array}$ & $\begin{array}{c}98 \\
(44.5 \%)\end{array}$ & $0.0022^{*}$ \\
\hline
\end{tabular}




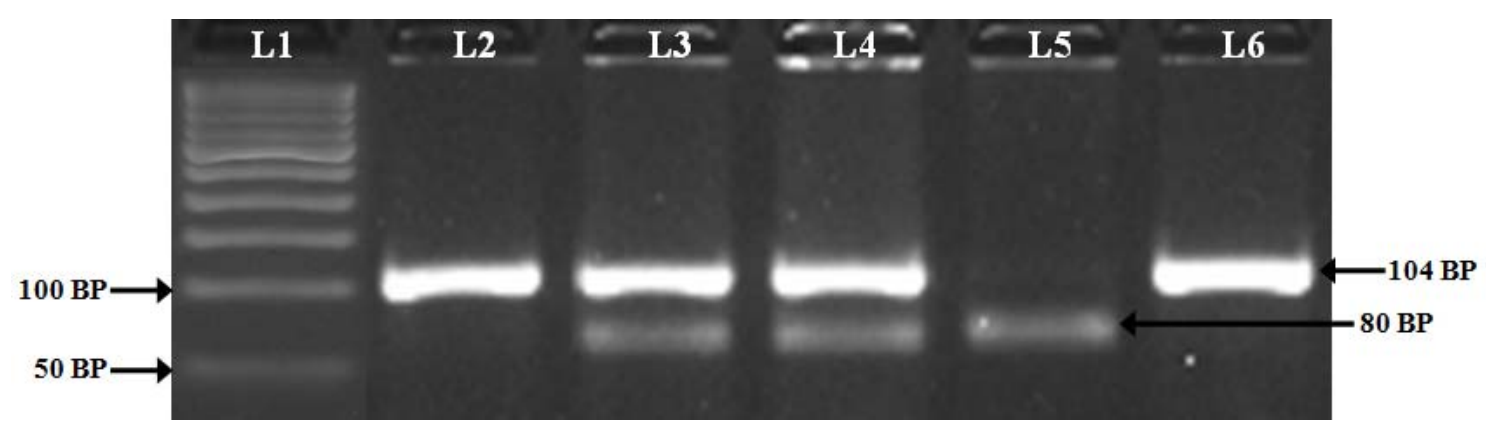

Figure 1. 3\% Agarose gel analysis of CYR61 (T $\rightarrow \mathbf{G})$ polymorphism. Lane 150 bp Ladder, Lane 2, 6 TT genotype 104bp, Lane 3,4 TG genotype 104, 80, 24 bp, Lane 5 GG genotype 80, 24 bp.

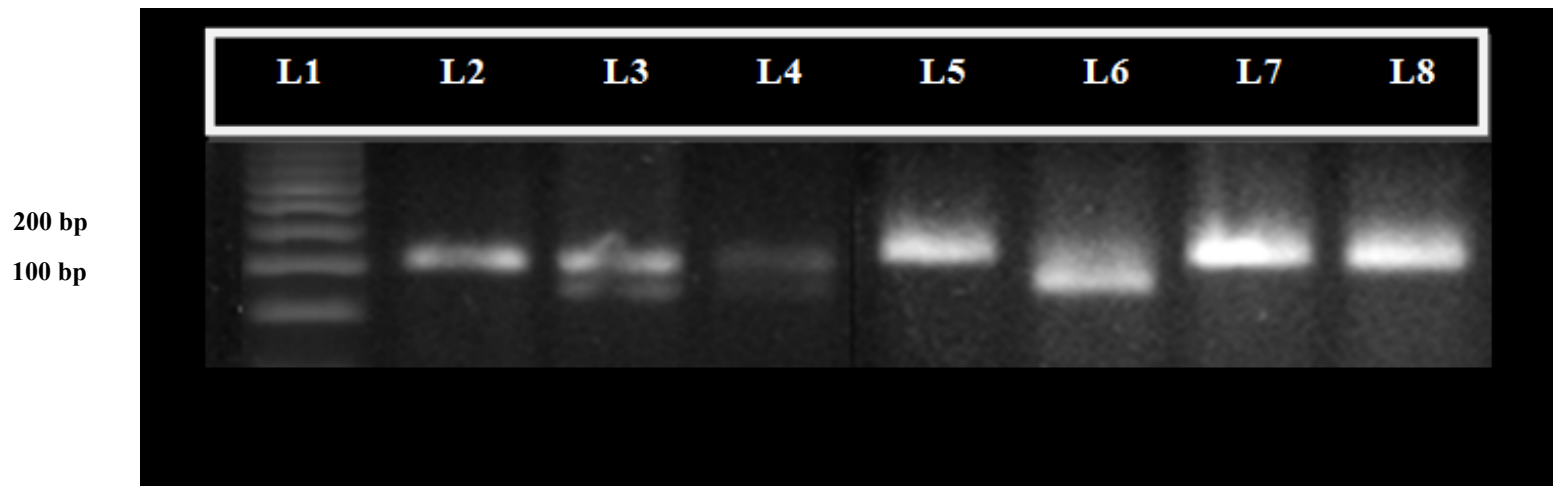

Figure 2.3\% Agarosegel electrophoresis analysis of MTHFR C677T polymorphism. Lane 2, 5, 7,8CC genotype (198 bp), Lane 3, 4 CTgenotype (198, 175, 23 bp), Lane 6 TT genotype (175, 23 bp) and Lane 1 Ladder 100bp 